\title{
TOO HARD TO MEASURE! MEASUREMENT OF SOCIAL MEDIA ACTIVITIES. AN OBJECTIVE-BASED PROCESS
}

\author{
Christopher ZERRES \\ Offenburg University, Germany \\ Email: christopher.zerres@hs-offenburg.de
}

DOI: 10.52846/MNMK.19.2.04

\begin{abstract}
:
Despite increasing budgets for social media activities and a wide variety of performance measurement possibilities, many companies do not measure the performance of their social media activities. Research shows that those companies that measure the performance of social media activities use incorrect, too few or inappropriate metrics. A central problem is that there is often an inadequate performance measurement process. This article presents a process that focuses on the objectives of social media activities. In phase one of this process, suitable metrics are selected and target values are defined based on these objectives. In phase two, data are collected and analysed. Finally, actions are defined. The developed process helps companies to measure the performance of their social media activities.
\end{abstract}

Keywords: Social media performance measurement, metrics, social media analytics, performance measurement process.

\section{Introduction}

Nowadays, many companies, regardless of their size and industry, use social media to communicate and interact with their different target groups. Research has shown that social media can increase brand awareness and sales, support companies' recruitment activities, improve the customer service and even has an influence on shareholder value (Babic Rosario et al., 2016; Gelper et al., 2018; Colicev et al., 2018). Due to the high potential of social media many companies spend high budgets on their social media activities (SMAs) (Statista, 2021). Spending high budgets also means that social media managers have to prove that the activities are successful and contribute to companies' objectives. The measurement and evaluation of SMAs requires a framework that consists of different steps. For example, Keegan and Rowley (2016) propose a six-stage framework: setting evaluation objectives, identifying key performance indicators (KPIs), identifying metrics, data collection and analysis, report generation, and management decision-making (Keegan and Rowley, 2016). Social media platforms as well as other companies provide tools which support this process by providing metrics and monitoring results. Especially in comparison with most other (offline) media, there are great options to measure the activities in social media, even in some cases the whole customer journey (Järvinen and Karjaluoto, 2015). For example, using the Facebook Pixel allows companies to track users from the first exposure to an ad on 
Facebook to the final conversion (e.g. purchase of a product on the company's online shop).

However, although there are adequate frameworks and many metrics available, companies struggle to measure the performance of their SMAs (Costa e Silva et al., 2020). McCann and Barlow (2014) for example found in their study that $65 \%$ of the companies they surveyed did not measure the return-on-investment $(\mathrm{ROI})$ of their SMAs (McCann and Barlow, 2014). Similar results were found in a US Study. Only $30 \%$ of the respondents reported the ability to prove the impact of social media (Moormann, 2021).

There are several reasons why companies may struggle to measure the performance of their SMAs:

- Companies may use only a few metrics such as likes or views, which are not helpful for evaluating SMAs and may even mislead marketing efforts (Peters et al., 2013).

- The dual nature of social media (the owned SMAs (controlled by the company) and the earned SMAs (neither directly generated nor controlled by the company)) makes it more complex to measure the performance (Costa e Silva et al., 2020).

- There are many different metrics and tools: a clear definition of objectives is necessary to choose suitable metrics and to find the appropriate tools.

- Social media measurement requires know-how (e.g. processes, social media analytics), time and financial investment (e.g. in tools). Often companies are not willing to invest this time or are simply not able to do so.

- Due to the high number of available metrics and the many objectives that can be achieved with SMAs, many companies struggle to define what exactly they want to measure. It is therefore important to have a clear understanding of what the company wants to achieve with its SMAs.

Although the topic is of very high importance from both a scientific and a practical point of view, there has been relatively little work on this subject to date. There are only a few studies dealing with a holistic approach (Agostino and Sidorova, 2016; Keegan and Rowley, 2016). Previous work has focused on specific aspects of social media performance measurement. One major focus here is metrics (Peters et al., 2013; Järvinen and Karjalouto, 2015). In addition, another focus of previous work is on the various methods of (social media) data collection and analysis (Stieglitz et al., 2018).

The aim of this paper is therefore to present a holistic approach for measuring social media performance. The approach developed in the article provides social media managers with a useful step-by-step approach to measuring the success of their SMAs. Additionally, examples of frequently used metrics are presented.

\section{Social media performance measurement}

Despite the growing importance of measuring the performance of SMAs, surprisingly little work has been done in this area (Järvinen and Karjaluoto, 2015). Accordingly, no generally accepted definition has yet been established. For an approximation and initial orientation, the definition of marketing performance measurement will be used first. According to Clark and Ambler (2001), marketing performance measurement is basically a matter of "...the assessment of the 
relationship between marketing activities and business performance" (p. 231). O'Sullivan and Abela (2008) summarise under the term marketing activities "... marketing communication, promotion, and other activities that represent the bulk of the typical marketing budget." (p. 80). The research on marketing performance measurement can be divided into three main areas: measurement of marketing productivity, identification of metrics in use, and measurement of brand equity (O'Sullivan and Abela, 2008).

In accordance with the definition of Homburg et al. (2017) social media performance is defined in this study as: "... the effectiveness and efficiency of an organisation's social media activities with regard to marketing and market-related goals, such as revenues, growth, and market share..." (p. 21). Based on this definition, the aim of social media performance measurement is to ensure the efficiency and effectivity of SMAs. Social media performance measurement requires a process in which goals, methods of data collection and analyses are defined. Based on these results, actions can be defined.

\section{Goal-oriented process}

Measuring the effectiveness and efficiency of SMAs requires a meaningful process (McCann and Barlow, 2014). There are various approaches available in this context, which are similar in many aspects. Table 1 provides an overview of a selection of such approaches.

\section{Selection of social media measurement approaches}

\begin{tabular}{|l|l|l|}
\hline Authors & Process & Study Type \\
\hline McCann and Barlow (2014) & Three stages: & Conceptual work \\
& 1) Planning stage (formulate goals, define objectives, outline metrics) & \\
& $\begin{array}{l}\text { 2) Implementation stage (implement appropriate social media tools, } \\
\text { choose methods for analysing social media, measure qualitative and } \\
\text { quantitative aspects of social media) } \\
\text { 3) Evaluation stage (evaluate short-term benefits, evaluate long-term } \\
\text { benefits, evaluate ROI) }\end{array}$ & \\
& $\begin{array}{l}\text { Starting point of the framework is the specific type of social media } \\
\text { contribution that needs to be measured: financial, network structure, } \\
\text { interactions, content of social media conversations and users' opinions } \\
\text { Agostino and Sidorova (2016) }\end{array}$ & Literature review \\
& $\begin{array}{l}\text { F) Mework consists of two main elements: } \\
\text { contributions) } \\
\text { 2) Methods (refers to the approaches to retrieving and analysing data) }\end{array}$ & \\
\hline Keegan and Rowley (2016) & $\begin{array}{l}\text { Six stages: } \\
\text { "Setting evaluation objectives", "Identifying KPIs", "Identifying } \\
\text { metrics", "Data collection and analysis", "Report generation" and } \\
\text { "Management decision-making" }\end{array}$ & 18 interviews with social media experts \\
\hline
\end{tabular}

Source: Developed by the author

The first step for a meaningful measurement of SMAs is a clear definition of the objectives to be achieved with the respective activity. All further steps build systematically on this clear definition of the objectives. In this context, Katsikeas et al. (2016) distinguish between performance outcomes related to marketing activities (operational performance) and performance outcomes related to the organisational performance. Operational performance describes the achievement of objectives 
within the company's value chain. The achievement of these operational objectives can in turn contribute to the achievement of objectives related to the organisational performance. Operational performance includes customer mindset (e.g. brand equity), customer behaviour (e.g. word of mouth), customer level performance (e.g. profitability) and product-market performance (e.g. unit sales). Organisational performance includes accounting performance (e.g. sales revenue) and financial market performance (e.g. investor returns).

This paper proposes a process that focuses on the importance of the objectives of SMAs. As shown in Figure 1, the starting point for measuring the performance of SMAs are the objectives to be achieved (organisational and operational objectives) and based on that the derivation of metrics and corresponding target values. This approach is in line with the fundamental requirement that metrics used for marketing performance measurement should always be based on corresponding marketing objectives (Järvinen and Karjaluoto, 2015). This is followed by the collection and analysis of data (e.g. using social media analytics) and, finally, the derivation of recommendations for action.

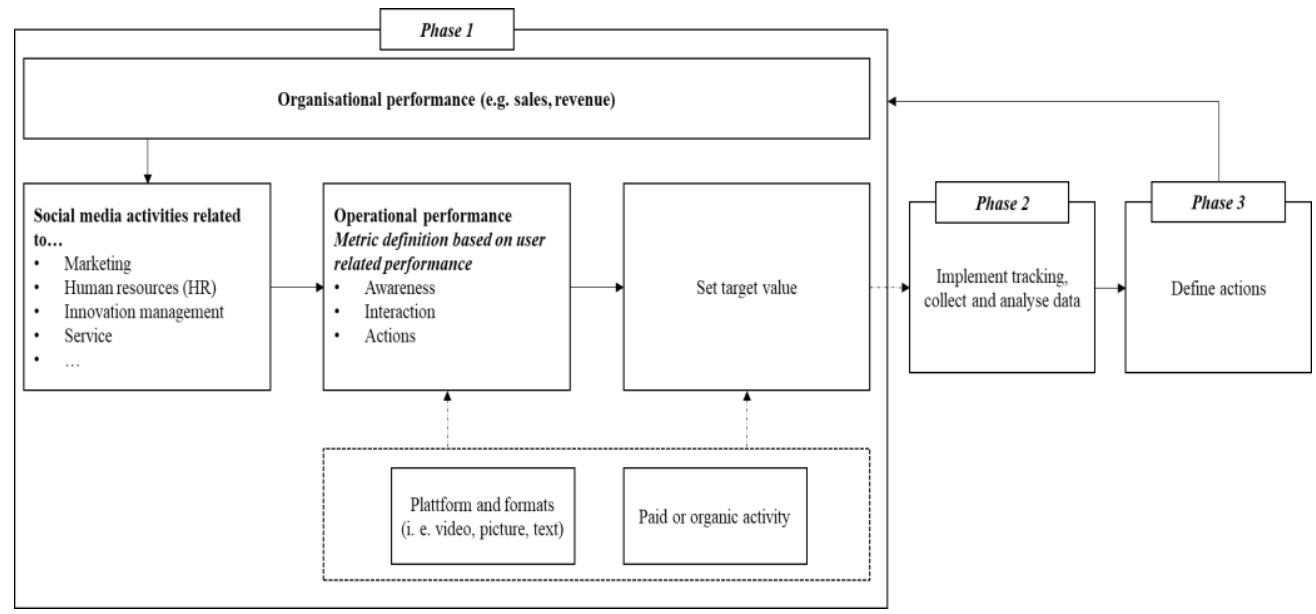

Figure 1. Social media measurement process

Source: Developed by the author

\section{Phase 1}

SMAs, like all other marketing activities, are used to achieve overarching corporate goals, i.e. to contribute to organisational performance (Muñoz-Expósito et al., 2017). Based on the corporate objectives (organisational performance), objectives are defined at the operational level (operational performance) to contribute to the achievement of these objectives, i.e. goal-setting in connection with specific marketing activities (Katsikeas et al., 2016). For example, SMAs are used to increase engagement with a brand (operational performance) so that the brand is subsequently demanded more frequently. Therefore, the higher sales for the brand contribute to the organisational performance (i.e. generating greater sales) (MuñozExpósito et al., 2017). In this context, Colisev et al. (2018), for example, point out that an indirect effect of SMAs on shareholder value is plausible through metrics 
such as brand awareness and purchase intention. The starting point for the objectives of individual SMAs discussed below are therefore always the higher-level objectives (organisational performance) of the company.

SMAs can be used for a wide variety of functional areas within a company (Risius and Beck, 2015). For example, SMAs can be used in marketing (e.g. creating awareness for products or selling services), in human resources management (e.g. drawing attention to vacancies or positioning the company as an interesting employer), in service (e.g. better complaint management), and in innovation management (e.g. generating ideas for improving services).

Within these areas, different objectives (outcomes) can be pursued. These objectives can be categorised using the funnel framework. According to this, the objectives are divided into the categories "Awareness", "Interaction" and "Action". In connection with these objectives, suitable metrics are selected. Figure 2 presents a selection of frequently used metrics for each category.

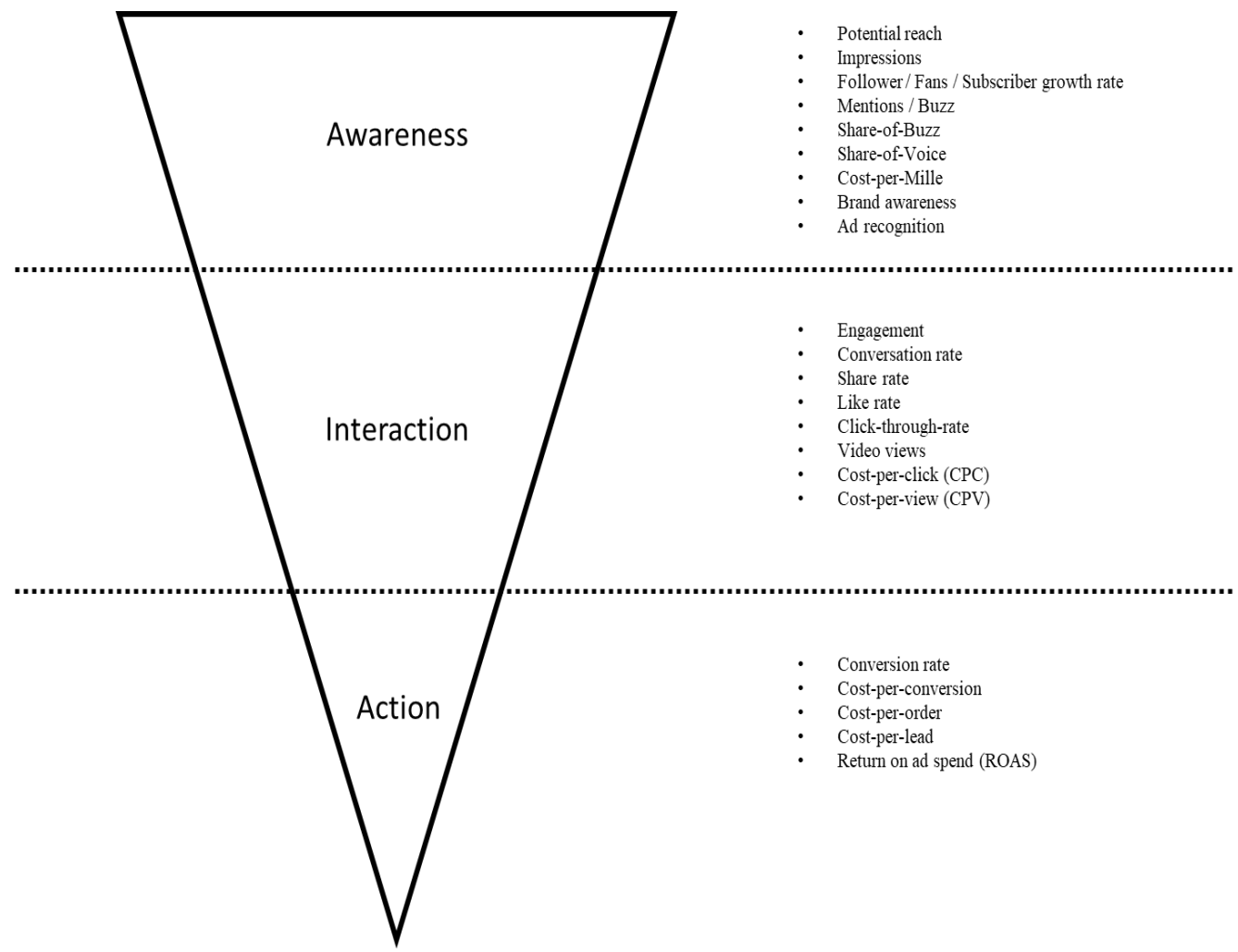

Figure 2. Examples of frequently used metrics for the different funnel categories

Source: Developed by the author 
a) Awareness: an important objective of many SMAs is to generate attention and awareness for a specific cause (e.g. for a product, a brand, a job advertisement). This category also includes advocacy and recommending certain brands and / or products. This objective, i.e. word-of-mouth-effects of social media, has already been addressed in numerous studies (Risius and Beck, 2015).

b) Interaction: SMAs are often used to trigger interaction and engagement. This involves motivating a user to interact with a particular object or agent (Hollebeek et al., 2014). Objects can be brands, offers, organisations or other activities of the organisation. This takes place independently of a purchase. Interactions and engagement can be very diverse in social media (also depending on the platform). An overview of the platform Twitter has been compiled by Muñoz-Expósito et al. (2017). Basically, there are different levels of engagement, which are for example recorded in dashboards. For example, a "Like" is rated lower than a "Comment" or a "Share" (Peters et al., 2013).

c) Action: Actions are defined by the company and are often called conversions. Conversions can be purchases, registrations for a newsletter or other types of action performed done by the user.

It is important to mention here that the presented categories are relevant for all types of SMAs regardless of the department for which they are used (human resources, marketing etc.).

In addition, when defining the objectives and metrics, the social media platform which is intended to be used needs to be considered. This will have an influence on the subsequent steps, since different metrics are used for videos than for texts, for example. Also, the individual platforms provide specific metrics that should be taken into account.

Another component that influences the specific definition and the subsequent steps is the decision to use paid media or owned media. In other words, is the company paying a platform (advertising) or an influencer to distribute content, or is the company using its owned channels to distribute content (for example, posting content on the Facebook company page). Both components are also particularly important for determining costs, which should be taken into account when defining metrics.

In many cases, costs are insufficiently considered when evaluating SMAs. Some costs cannot always be fully attributed to a particular activity. However, to have a realistic picture of the performance of SMAs, costs should be considered as far as possible. Possible costs include:

- Staff costs (e.g. for creating and distributing content, community moderation)

- Costs for ads

- Costs for influencers

- Costs for tools (e. g. monitoring tools)

- Costs for external service agencies / companies (e.g. an agency that creates content)

Based on the decisions made, a specific target value for the activity is defined. This target value can be used as the basis for a later evaluation. The following example illustrates the procedure described above (Figure 3 ). 


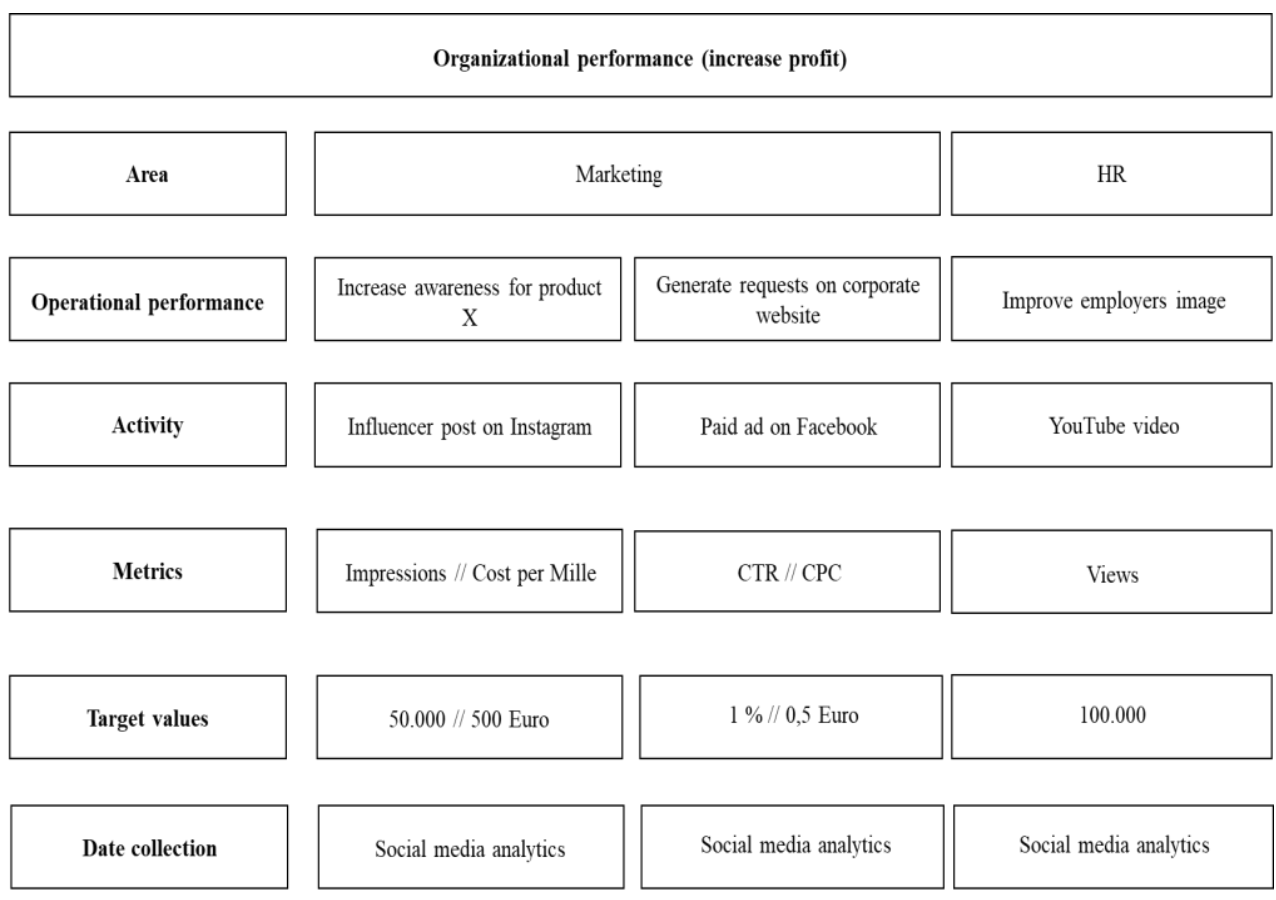

Source: Developed by the author

\section{Figure 3. Example}

\section{Phase 2}

Based on the objectives and metrics defined in the first phase, the necessary data is collected and analysed. Depending on the objective and metrics, different methods can be considered:

- Social media monitoring: Monitoring "...includes listening, interpreting, and taking action on what people are saying or otherwise conveying"(Zhang and Vos, 2014, p. 371; Rappaport, 2010). In particular, this involves finding out what comments and opinions users express in social media about the product, brand or company (Divol et al., 2012).

- Social media analytics: Is defined as "...an emerging interdisciplinary research field that aims at combining, extending, and adapting methods for analysis of social media data". (Stieglitz et al. 2018, p. 157; Zeng et al., 2010). According to Stieglitz et al. (2018) social media analytics comprise four stages: 1) Discovery; 2) Tracking; 3) Preparation; 4) Analysis.

- Web analytics: Web analytics is used to obtain information about users' clicking behaviour. This includes, for example, information about where the users of a website come from (e.g. search engines, display ads, social links) and the behaviour of users during their website visits. Pixel tracking methods (e.g. Facebook Pixel) can also be used to track significant aspects of user behaviour even across channels. 
- Market research: Relevant market research methods include surveys (e.g. for objectives related to brand awareness) and experiments (e.g. A/B testing related to click behaviour on social media ads).

- Internal departments: Data can also be collected from internal departments. Here, controlling, accounting, or other departments affected by or involved with the social media activity (e.g. human resources) are typical examples. For example, information regarding invoiced hours for the creation of content can be collected from accounting.

Various tools can be used to access, collect and analyse the data, depending on the measurement objective. For the first three options mentioned above, a platform's own tools can be used (e.g., Twitter Analytics or the Facebook Business Manager) (McCann and Barlow, 2014; Agostino and Sidorova, 2016). Google Analytics also plays an important role here, especially if data is to be collected outside the specific platform. In addition, there are tools that enable platformindependent data collection and analysis (e.g. Hootsuite). A dashboard can be an effective tool. Pauwels et al. (2008) define a dashboard as "...a relatively small collection of interconnected key performance metrics and underlying performance drivers that reflects both short- and long-term interests to be viewed in common throughout the organisation." (p. 177).

\section{Phase 3}

In the last phase, actions are derived based on the information obtained. These actions may address the following areas:

- Evaluation of actual SMAs: the process allows a simple evaluation of the existing SMAs by a comparison of the defined target value to the value achieved by the respective SMAs after a predefined period. If there is a negative difference managers need to evaluate and decide which aspect of the SMAs is responsible for the difference i.e. the negative performance. Possible aspects are for example: the creative was not suitable or appealing enough, the target group was not well defined.

- Supporting the planning process of future SMAs: this includes for example the right budget allocation, defining the target group, choosing the appropriate channels, creating content.

- Supporting and improving the measurement process: the evaluations also help to improve the measurement process since the results can be directly used in phase 1 (e.g. by setting appropriate and realistic target values).

In addition the results of the measurement process need to be reported to the different internal stakeholders.

\section{Conclusion}

SMAs are playing an increasingly important role in companies' communications mix. The paper clearly indicates that companies still have a long way to go in this respect, despite the wide range of options for measuring the success of SMAs. The developed process supports managers in successfully measuring the performance of their SMAs.

In addition to the proposed process managers should consider the following recommendations regarding the measurement of SMAs. The used metrics should 
be reviewed once or twice a year. There might be new (more) suitable metrics. It is also important to define an appropriate number of metrics and to define how often they are tracked. Metrics could be evaluated for example on a weekly or monthly basis. It is also possible to track on specific occasions (e.g. a special campaign). The used metrics and especially the benefits of measuring SMAs should be communicated transparently. It is crucial that everyone understands why it is important to spend time and money on measuring the SMAs. Furthermore, the costs related to SMAs should be calculate realistically and should be considered when evaluating SMAs. Companies need to be aware that the data collection and analysis requires at least some level of IT, technical and statistic skills. Therefore, this requirement should be considered when selecting the responsible persons. Finally, companies should use tools which support the process, especially when it comes to data collection and the analyses of this data.

It is important to note that due to the different conditions that may apply (products, services, company size, customer structure, etc.) each company must modify their process individually, and continuously need to critically evaluate this process and its components. Although the presented model is developed for all types of organisations further research could investigate the impact of different conditions like the company size or the types of products and services offered on the usability and effectiveness of the model. In addition further research could empirically test the proposed model.

\section{REFERENCES}

Agostino, D., \& Sidorova, Y. (2016), "A performance measurement system to quantify the contribution of social media: new requirements for metrics and methods", Measuring Business Excellence, 20(2), 38-51.

Babic Rosario, A., Sotgiu, F., de Valck, K., \& Bijmolt, T.H.A. (2016), "The Effect of Electronic Word of Mouth on Sales: A Meta-Analytic Review of Platform, Product, and Metric Factors", Journal of Marketing Research, 53(3), 297-318.

Clark, B.H., \& Ambler, T. (2001), "Marketing Performance Measurement: Evolution of Research and Practice", International Journal of Business Performance Management, 3 (Winter), 231-244.

Coleman, J.E., \& Heriot, K.C. (2014), "Social Media Effectiveness for Small Businesses: Concept and Measurement", Journal of Business and Economics, 5(6), 769-774.

Colicev, A., Malshe, A., Pauwels, K., \& O'Connor, P. (2018), "Improving Consumer Mindset Metrics and Shareholder Value Through Social Media: The Different Roles of Owned and Earned Media", Journal of Marketing, 82 (January 2018), 37-56.

Costa e Silva, S., Duarte, P.A.O., \& Almeida, S.R. (2020), "How companies evaluate the ROI of social media marketing programmes: insights from B2B and B2C", Journal of Business \& Industrial Marketing, 35/12 (2020), 2097-2110. 
Divol, R., Edelman, D., \& Sarrazin, H. (2012), "Demystifying social media”, McKinsey Quarterly, 2012 No. 2, 66-77.

Gelper, S., Peres, R., \& Eliashberg, J. (2018), "TalkBursts: The Role of Spikes in Prerelease Word-of-Mouth Dynamics", Journal of Marketing Research, 55(6), 801-17.

Hollebeek, L.D., Glynn, M.S. \& Brodie, R.J. (2014), "Consumer brand engagement in social media: conceptualization, scale, development and validation", Journal of Interactive Marketing, 28(2), 149-165.

Homburg, C., Grozdanovic, M., \& Klarmann, M. (2007), "Responsiveness to Customers and Competitors: The Role of Affective and Cognitive Organizational Systems", Journal of Marketing, 71(3), 18-38.

Järvinen, J., \& Karjaluoto, H. (2015), "The use of Web analytics for digital marketing performance measurement”, Industrial Marketing Management, 50 (October), 117-127.

Katsikeas, C.S., Morgan, N.A., Leonidou, L.C. \& G. Hult G.T.M. (2016), "Assessing Performance Outcomes in Marketing", Journal of Marketing, 80 (March 2016), $1-20$.

Keegan, B.J., \& Rowley, J. (2016), "Evaluation and decision making in social media marketing", Management Decision, 55(1), 15-31.

McCann, M., \& Barlow, A. (2014), "Use and measurement of social media for SMEs", Journal of Small Business and Enterprise Development, 22(2), 273-287.

Moormann, C. (2021), "Top Ten Results from the February 2020 CMO Survey", The CMO Survey, available at: https://cmosurvey.org/top-ten-results-from-thefebruary-2020-cmo-survey/ (accessed 24th August, 2021).

Muñoz-Expósito, M., Ángeles Oviedo-García, M., \& Castellanos-Verdugo, M. (2017), "How to measure engagement in Twitter: advancing a metric", Internet Research, 27(5), 1122-1148.

O'Sullivan, D., \& Abela, A.V. (2007), "Marketing Performance Measurement Ability and Firm Performance", Journal of Marketing, Vol. 71 (April 2007), 79-93.

Pauwels, K., Ambler, T., Clark, B.H., LaPointe, P., Reibstein, D., Skiera, B., Wierenga, B., \& Wiesel, T. (2009), "Dashboards as a Service: Why, What, How, and What Research Is Needed?", Journal of Service Research, 12(2), 175189.

Peters, K., Chen, Y., Kaplan, A. M., Ognibeni, B., \& Pauwels, K. (2013), "Social media metrics: A framework and guidelines for managing social media", Journal of Interactive Marketing, 27, 281-298.

Rappaport, S. D. (2010), "Listening solutions", Journal of Advertising Research, $50(2), 197-213$.

Risius, M., \& Beck R. (2015), "Effectiveness of Corporate Social Media Activities to Increase Relational Outcomes", Information and Management, 52 (2015), 824839.

Statista (2021), "Social Media Advertising", available at: https://www.statista.com/outlook/dmo/digital-advertising/social-media-advertising/worldwide (accessed 24th August, 2021). 
Stieglitz, S., Mirbabaie, M., Ross, B., \& Neuberger, C. (2018), "Social media analytics - Challenges in topic discovery, data collection, and data preparation", International Journal of Information Management, 39(2018), 156-168.

Zhang, B., \& Vos, M. (2014), "Social media monitoring: methods, benefits and difficulties for international companies", Corporate Communications: an International Journal, 19(4), 371-383.

Zeng, D., Chen, H., Lusch, R., \& Li, S. H. (2010), "Social media analytics and intelligence", IEEE Intelligent Systems, 25(6), 13-16. 